\title{
DIRETOR: O PROTAGONISTA DA GESTÃO ESCOLAR
}

\author{
João Guedes dos Anjos' ${ }^{1}$ \\ Patrícia da Silva Bispo ${ }^{2}$
}

\begin{abstract}
Resumo
Este artigo tem como objetivo geral apresentar a importância do diretor para a condução do processo de democratização no seio escolar desconstruindo uma ideia pré concebida de que este está a serviço do poder governante. E que são as habilidades e conhecimentos específicos que a função exige, que torna o diretor o mais qualificado para coordenar e mediar as relações implícitas em todo o processo de democratização do ensino ofertado. De certo que a formação inicial do professor não o prepara com mais afinco para esta função no sentido de administrar. Contudo o mais importante é constituído em sua formação que é o saber pedagógico. Afinal, o principal objetivo da escola é a aprendizagem. Os temas apresentados se comunicam com o objeto de estudo. Espera-se que este estudo possa contribuir para formação de gestores escolares na perspectiva de ampliar saberes e práticas relativos a gestão escolar.
\end{abstract}

PalavraS chave: Diretor, Gestão Escolar, Democratização.

\begin{abstract}
This article aims to present the importance of the director for conducting the process of democratization within the school by deconstructing a preconceived idea that it is at the service of the governing power. And that it is the specific skills and knowledge that the function requires, that makes the director the most qualified to coordinate and mediate the relationships implicit in the whole process of democratization of the offered teaching. Certainly, the initial training of the teacher does not prepare him more hard for this function in order to administer. However, the most important is constituted in their formation which is pedagogical knowledge. After all, the main goal of the school is learning. The themes presented communicate with the object of study. It is expected that this study can contribute to the training of school managers in the perspective of expanding knowledge and practices related to school management.
\end{abstract}

Key word: Principal, School Management, Democratization.

\section{INTRODUÇÃO}

\author{
Este artigo discute a importância da figura do diretor como principal \\ protagonista no contexto da democratização da educação, que sem a sua
}

\footnotetext{
${ }^{1}$ Doutorando em Ciências da Educação pela Faculdade Interamericana de Ciências Sociais - FICS. Mestre em Ciências da Educação pela Faculdade Interamericana de Ciências Sociais - FICS. Especialista em arte Educação pelo Centro Universitário Leonardo Da Vinci. Especialista em Gestão Integrada: Administração, Supervisão e Inspeção pelo Instituto Superior de Educação Afonso Cláudio. Graduado em Pedagogia pela Faculdade de Tecnologia e Ciências - FTC. Docente do Ensino Fundamental pela Secretaria de Educação do Município de Camaçari. Email: guedes411@hotmail.com

${ }^{2}$ Mestre em Ciências da Educação pela Faculdade Interamericana de Ciências Sociais - FICS. Especialista em História da África pela UFRB.Especialista em Psicopedagogia pela FAC. Licenciada em Pedagogia pela UEFS. Docente da Rede Municipal de Educação de Santo Amaro-Ba. Email:. patinhaprof@gmail.com
} 
representatividade poderá gerar o comprometimento do processo democrático no interior da escola.

Está atrelada na figura do diretor, a liderança, mediação, o conhecimento específico na relação de pessoas e o mais importante, o conhecimento pedagógico. São estas especificidades que fazem do diretor a figura que representa os anseios de uma comunidade escolar.

Por tanto, o reconhecimento da relevância do exercício da função de diretor requer uma atenção especial na qual seja possível qualificar a gestão escolar e por conseguinte um ensino de qualidade.

De certo que,muitos fatores interferem na aprendizagem, tais como, inadequação de métodos específicos às particularidades dos educandos, a escolha da metodologia baseada nas diferentes necessidades e dificuldades que os indivíduos apresentam, aplicação de currículos sem fundamentação teórica, não sendo respeitados os reais níveis etários, e possibilidades instrumentais dos alunos, que acarretam em exigências aquém ou além da competência dos alunos.

É possivel que com um diretor com habilidades e competencias especificas para a função de gestor, esse fatores podem ser atenuados ou até solucionados. Ainda persiste a ideia, de que o diretor é uma pessoa de "confiança do grupo político que governa. Uma ideia que é contraditória com o principio da direção no contexto da gestão democrática a qual, está no compromisso do diretor que é ser representante da comunidade, logo este precisa ser de "confiança comunidade. Esta credibilidade com a comunidade é concedida e legitimada pelo processo de escolha promovido pela eleição.

\section{A Gestão Na Proposta Democrática}

Gestão Democrática é uma tendência de gestão da escola pública que tem sido campo de debate, de sonhos e proposições. A constituição Federal, a LDB 9.394/96, o Documento Referência do CONAE 2010 e intelectuais comprometidos com essa preocupação têm explicitado a urgência dessa gestão como princípio que implica na melhoria da qualidade social

O entendimento do que seja gestão democrática tem seu contorno éticopolítico e epistemológico, de maneira que ROCHA e SILVA (2009) apresentam uma percepção muito importante, ao dizer que: 
A gestão democrática e participativa com qualidade pedagógica na escola pública deve ser entendida como uma ação que caracterize a efetiva participação da comunidade escolar nas tomadas de decisão. Só assim será possível conceber uma escola pública realmente atrelada aos interesses de seu público e do público em geral (ROCHA e SILVA 2009, p. 10).

Diante desse contexto, entende-se que a consolidação de uma gestão escolar de cunho democrático-participativo, requer competência cognitiva e afetiva, respaldada na internalização de valores, hábitos, atitudes e conhecimentos. Diante disso, a equipe escolar pode adaptar-se às novas possibilidades gestoras e pedagógicas, buscando aprimorar-se, com base teórica e prática sobre gestão democrática, onde ela possa exercer autonomia pedagógica e administrativa e de gestão financeira.

A gestão democrática evidencia uma compreensão da gestão escolar ao dizer que ela corresponde ao processo de gerir na dinâmica do sistema de ensino como um todo e coordenação das escolas em especifico, afinado om diretrizes e políticas educacionais públicas, para implementação das políticas educacionais e projetos pedagógicos das escolas compromissado com os princípios da democracia com métodos que organizem e criem condições para um ambiente educacional autônomo( soluções próprias, no âmbito de suas competências) de participação e compartilhamento ( tomada conjunta de decisão e efetivação de resultados), autocontrole (acompanhamento e retorno de informação)e transparência (demonstração pública de seus processos e resultados( CARNEIRO 2015)

\section{A relação do diretor com a gestão escolar}

Ao diretor não compete somente as questões de administração burocráticas, mas também é principalmente os aspectos pedagógicos o qual é o núcleo de toda intencionalidade da unidade escolar sob a responsabilidade da gestão. $O$ desenvolvimento e eficácia de uma qualidade educativa, envolve a gestão escolar que desenvolve suas funções com objetivo da criação de ambiente favorável, promovendo oportunidades para a formação profissional, autoformação, pesquisa, experimentos, debates e reflexão pedagógica e gerencial no interior da escola.

Esta concepção, é compartilhada a partir das ideias de Libâneo quando este declara que:

A direção é um princípio e atributo da gestão, mediante a qual é canalizado o trabalho conjunto das pessoas, orientando-as e integrando-as no rumo dos objetivos. Basicamente, a direção põe em ação o processo de tomada 
de decisões na organização, e coordena os trabalhos de modo que sejam executados da melhor maneira possível (LIBÂNEO, 2015, p.88).

Para que a escola, efetivamente seja capaz de alcançar o objetivo que the foi outorgado pela sociedade, para atender a sistematização do processo internacional, faz-se necessário o processo de tomada de decisão a definir a partir de ações específicas da gestão (LIBANEO, OLIVEIRA e TOCHI, 2012).

Os instrumentos e práticas de gestão escolar são em geral a mistura de democracia representativa - instrumentos e instâncias formais que pressupõem a eleição de representantes, com democracia participativa - estabelecimento de estratégias e fóruns de participação direta, articulados e dando fundamento a essas representações. E nesse contexto, pode-se destacar que a gestão é a atividade pela qual "são mobilizados meios e procedimentos para garantir os objetivos da organização, envolvendo, basicamente, os aspectos gerenciais e técnicoadministrativo" (LIBANEO; OLIVEIRA; TOCHI, 2012, p.438).

Contudo, sabe-se que a gestão representada na figura do diretor não é capaz de assumir sozinha a responsabilidade da almejada qualidade de ensino. Todavia ela é compreendida como um forte aliado, neste processo, considerando que é a gestão a representante de toda a comunidade escolar e quem promove a estreita relação com o sistema de ensino, pois:

O termo gestão da educação quando se associa à escola, e trabalha com a concepção sócio crítica de gestão escolar. Nessa concepção, a gestão de educação também é engendrada como um sistema que agrega pessoas, considerando o caráter intencional de suas ações e as interações sociais que estabelecem entre si e com o contexto sócio-político, nas formas democráticas de tomada de decisões (LIBÂNEO, 2007, p. 324).

Dessa forma a participação significa intervenção dos profissionais da educação e representantes da comunidade, que articulados entre si, proporcionam melhor conhecimento dos objetivos e metas da escola.

Diante disso, é crescente a preocupação da sociedade quanto ao perfil de liderança desses profissionais, haja vista que para se ter uma boa qualidade no ensino, é preciso ter um bom líder, um bom diretor, enfim, um bom gestor. A questão da liderança é um ponto importante para a qualidade do ensino, considerando a capacidade de influência do líder no âmbito da gestão de pessoas e de processos sociais, no sentido de mobilização de seus talentos, orientados por uma visão clara e abrangente da organização em que se situa e de objetivos que a equipe se propõe a realizar (LUCK, 2011 
Nessa perspectiva, a gestão é compreendida como elo na relação do sistema de ensino com os interesses da comunidade escolar. Está na gestão a função de contribuir no processo de empoderamento da comunidade em sua relação com o sistema de ensino, confirmando a concepção da gestão democrática como modelo de gestão escolar, com potencial para garantir a qualidade do ensino público.

E o gestor exerce o papel fundamental que é o de liderar e/ou conduzir uma equipe, com a finalidade de promover um ambiente harmonioso com todos trabalhando para uma educação de qualidade, porque:

\begin{abstract}
A liderança participativa é uma estratégia empregada para aperfeiçoar a qualidade educacional. Constitui a chave para liberar a riqueza do ser humana que está presa a aspectos burocráticos e limitada dentro do sistema de ensino e a partir de práticas orientadas pelo senso comum ou hábitos não avaliados. Baseado em bom senso, a delegação de autoridades àqueles que estão envolvidos na realização de serviços educacionais é construída a partir de modelos de liderança compartilhada, que são os padrões de funcionamento de organizações eficazes e com alto grau de desempenho ao redor do mundo (LÜCK. 2005 p.35).
\end{abstract}

A função do gestor é desenvolver uma liderança amigável sabendo minimizar de trabalhar com os conflitos e as diversidades de personalidades, vez que cada indivíduo traz para o convívio social e escolar suas peculiaridades e culturas, então o gestor deve estar preparado para buscar alternativas que atenda o interesse de todos.

Assim, na dinâmica do processo de gestão do espaço escolar, é constatado a correspondência com a dinâmica do sistema de ensino perante a comunhão com as políticas públicas e as diretrizes que as asseguram. É no entendimento dessa correspondência da tríplice aliança que envolve políticas públicas, sistema de ensino e gestão, que caracteriza como relevante a atuação da gestão escolar pública representada na figura do diretor, por ser aquele que se relaciona com mais proximidade com a comunidade escolar, como o agente que coordena as ações para efetivamente pôr em prática as políticas públicas, determinadas ao sistema de ensino, contribuindo para o exercício da função social da escola.

Tecendo considerações determinantes no desvelo com a democratização no ensino público, pode-se abordar que:

A gestão democrática do ensino público é fundamental para a ultrapassagem de práticas sociais alicerçadas na exclusão, na discriminação e na apartação social. Práticas que inviabilizam a construção histórico-social dos sujeitos. Neste sentido a ingerência político-partidária na 
gestão escolar é antidemocrática e deformadora dos interesses educacionais (CARNEIRO, 2015, p.74).

Nota-se nas ideias do autor uma crítica a interferência político-partidária que permeia o espaço escola com a indicação da gestão, a falácia de uma autonomia concedida a escola que na prática, por razões de autarquias não ocorre com o ideário de democracia.

Mesmos após muitas transformações e intervenções das políticas públicas para melhorar a qualidade de ensino, no Brasil ainda não existe uma normatização específica quanto ao provimento para gestor escolar, cedendo autonomia aos municípios para adotar o modelo pelo qual será indicado o profissional para a função de gestor da escola pública, seja por meio de concurso, por eleição ou por indicação. Esta última, no entanto, configura uma contradição para com a ideia nuclear da Gestão Democrática instituída legalmente para a gestão da educação pública (CARNEIRO, 2015).

Adotar a indicação como modelo para a gestão escolar, fere os padrões de liberdade e de direitos da comunidade escolar, em negar-Ihes a participação direta no processo de escolha partindo dos princípios de democratização do ensino normatizados pela LDB.

A inexistência de uma legislação específica que constitua determinações específicas para essa finalidade, possibilita que em muitas escolas públicas e em especial algumas escolas municipais, padecem com a gestão escolar desqualificada, pois, estas estão sob judicie do poder público local, que caracteriza a gestão em toda sua constituição como cargos de confiança do poder político local, quando deveria ser de confiança da comunidade escola.

\section{Considerações}

Pode-se afirmar que a relevância da gestão para a qualidade da educação ainda não está consolidada. Por esse motivo, o município ainda não apresenta exigências claras quanto a formação, capacitação e habilidades para o exercício da função de gestor escolar. Essa ausência de especificidade para o exercício da gestão, evidencia que o município ainda não visualiza o gestor escolar com o subsídio para uma educação de qualidade 
Assumir a gestão da escola por indicação, a qual a menospreza as especificidades das atribuições inerentes a função de gestor, é negligenciar as primícias da democracia.

A necessidade de possuir habilidades e competências para atuação na gestão escolar, compreendendo a importância e utilização dos instrumentos da gestão democrática com o entendimento de que as ações administrativas são pensadas para atender as ações pedagógicas constituem o fazer didáticoadministrativo do gestor escolar.

Desse modo, entende-se que para a composição da gestão escolar especificamente em relação às escolhas dos diretores e outros membros que compõem a gestão, bem como os critérios dessa escolha, quando não passa por um processo de eleição, os requisitos necessários para investidura no cargo de diretor e vice diretor são menosprezados, e o exercício da função de diretor perde a devida importância no processo de democratização no espaço escolar.

Nesse sentido, acreditar-se que a gestão escolar representada na figura do diretor, é quem conhece as necessidades e especificidades do público sendo este conhecimento um fator importante que influencia nos resultados positivos da educação.

\section{Referencias:}

BRASIL. Lei de Diretrizes e Base da Educação n9394/96. Brasília. 1996.

BRASIL. Lei de Diretrizes e Base da Educação Lei 11. 301/ 2006. Brasília. 2006. BRASIL. Lei do Plano Nacional de Educação, Lei no 13.005/2014. Brasília. 2014. BORDIGNON, G; GRACINDO, R. V. Gestão da educação: o município e a escola. In: FERREIRA, N. S. C; AGUIAR, M. (Org.). Gestão da educação: impasses, perspectivas e compromissos. São Paulo: Cortez, 2001.

CARNEIRO, M.A. LDB Fácil. Leitura crítico compreensiva, artigo a artigo. Petrópolis-Rio de Janeiro, 2015.

CHARLOT, B. Da Relação com o Saber: Elementos para uma teoria. Porto Alegre; Artes Médicas Sul, 2000.

CARNEIRO, M. A. LDB fácil: leitura crítica e compreensiva.23. Ed. Petrópolis, Rio de Janeiro: Vozes, 2015.

FREIRE, P. Pedagogia da Autonomia: Saberes necessários à prática educativa, 35. ed. São Paulo: Paz e Terra, 1997.

GADOTTI, M;ROMÃO, J. E. Autonomia da Escola: princípios e propostas. São Paulo. Cortez, 2013.

HERNÁNDEZ, F. Cultura visual: Mudança educativa e projeto de trabalho. Porto Alegre: Artmed.2003.

IMBERNÒN, F. Formação docente e profissional: forma-se para mudança e a certeza. São Paulo: Cortez, 2001. 
KIRK, S.A.; KIRK, W.D. Ao definir dificuldades de aprendizagem. Journal of Learning Disabilities, 1983

LEMOS, A. A Comunicação das coisas: Teoria ator- -rede e cibercultura. São Paulo: Annablume, 2013.

LIBÂNEO, J. C. Organização e gestão da escola: teoria e prática. Goiânia: Alternativa, 2004.

LIBÂNEO, J. C Educação escolar, políticas, estruturas e organização. 2 ed. São Paulo: Cortez, 2005.

LIBÂNEO, J. C. A organização e a gestão da escola: teoria e prática. Goiânia: Alternativa, 2007.

LIBÂNEO. J. C. Pedagogia, Ciência da educação? São Paulo: Cortez, 2012.

LIBÂNEO. J. C..Organização da Gestão Escolar. Teoria e Pratica. São Paulo .ed 6 a ed. HECCUS editora.2013.

LIBÂNEO, J. C. Organização e gestão da escola: teoria e prática. $6^{a}$ edição. São Paulo, Heccus, 2015.

LIBÂNEO, J. C; OLIVEIRA, J.F.; TOSCHI, M. Educação escolar:política,estrutura e organização. 10. Ed. Cortez Editora. São Paulo. 2012

LÜCK, H.. Em Aberto/Instituto Nacional de Estudos e Pesquisas Educacionais. Brasília: O Instituto, 1981.

LUCK, H. (Org.). Gestão Escolar e Formação de Gestores. In: Revista em aberto, v. 17, Brasília, jun. 2000.

LÜCK, H. et.al. A escola participativa: 0 trabalho do gestor escolar. 5.ed. Petrópolis: Vozes, 2005.

LÜCK, H. Dimensões da Gestão Escolar e suas Competências Curitiba. Positivo. 2009.

LÜCK, H. Gestão Participativa na Escola. Rio de Janeiro. Vozes. 2011.

LÜCK, H. A Gestão Participativa na Escola. Florianópolis. Santa Catarina. Vozes. 2013. 